\title{
Endometrial mesenchymal stem/ stromal cells: The Enigma to code messages for generation of functionally active regulatory T cells
}

\author{
Mehdi Aleahmad', Mahmood Bozorgmehr ${ }^{2,3}$, Shohreh Nikoo ${ }^{3}$, Alireza Ghanavatinejad', \\ Mohammad-Reza Shokri ${ }^{1}$, Samaneh Montazeri ${ }^{2}$, Fazel Shokri ${ }^{1 *}$ and Amir-Hassan Zarnani ${ }^{1,2,3^{*}}$
}

\begin{abstract}
Background: Regulatory T cells (Tregs) play an important role in fine-tuning of immune responses and are pivotal for a successful pregnancy. Recently, the importance of mesenchymal stem cells in regulation of immune responses in general and Tregs in particular has been highlighted. Here, we hypothesized that menstrual stromal/stem cells (MenSCs) contribute to uterine immune system regulation through induction of functionally active Tregs.

Methods: MenSCs were collected from 18 apparently healthy women and characterized. Bone marrow mesenchymal stem cells (BMSCs) served as a control. The effect of MenSCs on proliferation of anti-CD3/CD28-stimulated T CD4 + cells and generation of Tregs with or without pre-treatment with mitomycin C, IFN- $\gamma$ and IL-1 $\beta$ was evaluated by flow cytometry. The potential role of IDO, PGE2, IL-6, IL-10, and TGF- $\beta$ on proliferation of T CD4 + cells and generation of Tregs was assessed using blocking antibodies or agents. IDO activity was evaluated in MenSCs and BMSCs culture supernatants by a colorimetric assay. IL-10 and IFN- $\gamma$ production in MenSCs-primed T CD4 + was measured using intracellular staining. To investigate the functional properties of Tregs induced by MenSCs, Treg cells were isolated and their functional property to inhibit proliferation of anti-CD3/CD28-stimulated PBMCs was assessed by flow cytometry.

Results: According to the results, proliferation of T CD4 + lymphocytes was enhanced in the presence of MenSCs, while pre-treatment of MenSCs with pro-inflammatory cytokines reversed this effect. PGE2 and IDO were the major players in MenSCs-induced T cell proliferation. Non-treated MenSCs decreased the frequency of Tregs, whereas after pre-treatment with IFN- $\gamma$ and IL-1 $\beta$, they induced functional Tregs with ability to inhibit the proliferation of anti-CD3/ CD28-stimulated PBMCs. This effect was mediated through IL-6, IL-10, TGF- $\beta$ and IDO. IFN- $\gamma / \mathrm{IL}-1 \beta$-treated MenSCs induced IL-10 and IFN- $\gamma$ production in CD4 + T cells.
\end{abstract}

Conclusion: Collectively, these findings indicate that immunomodulatory impact of menstrual blood stem cells (MenSCs) on generation of Tregs and inhibition of T cells proliferation is largely dependent on pre-treatment with IFN- $\gamma$ and IL-1 $\beta$. This is the first report on immunomodulatory impact of MenSCs on Tregs and highlights the pivotal role of endometrial stem cells in regulation of local endometrial immune responses.

*Correspondence: fshokri@tums.ac.ir; fazshok@yahoo.com; Zarnania@tums.

ac.ir; Zarnania@gmail.com

${ }^{1}$ Department of Immunology, School of Public Health, Tehran University

of Medical Sciences, P.O. Box: 1417613151, Tehran, Iran

Full list of author information is available at the end of the article permits use, sharing, adaptation, distribution and reproduction in any medium or format, as long as you give appropriate credit to the original author(s) and the source, provide a link to the Creative Commons licence, and indicate if changes were made. The images or other third party material in this article are included in the article's Creative Commons licence, unless indicated otherwise in a credit line to the material. If material is not included in the article's Creative Commons licence and your intended use is not permitted by statutory regulation or exceeds the permitted use, you will need to obtain permission directly from the copyright holder. To view a copy of this licence, visit http://creativecommons.org/licenses/by/4.0/. The Creative Commons Public Domain Dedication waiver (http://creativeco mmons.org/publicdomain/zero/1.0/) applies to the data made available in this article, unless otherwise stated in a credit line to the data. 
Keywords: MenSCs, Regulatory T cells, Proliferation, Endometrium, Pregnancy, Immunomodulation

\section{Background}

Regulatory $\mathrm{T}$ cells (Tregs), as one of the main regulators of the immune system, play an important role in fine-tuning of immune responses and preventing autoimmunity. The presence of Tregs in the uterus and their positive impact in successful pregnancy have been fully understood $[1,2]$. The frequency of circulatory Tregs in non-pregnant fertile women reaches to the highest level between days 9 to 13 of follicular phase and reduces during the luteal phase of the menstrual cycle [3], which is believed to be essential to prepare the uterus for encountering the paternal antigens and possible implantation [4]. Along with that, it is known that same alteration in Treg population can be observed in murine estrus cycle [5].

In very early stages of human pregnancy, systemic and local frequency of Tregs in decidua, lymph nodes and spleen is increased and reaches its peak on second semester of gestation $[2,6,7]$. Treg frequency is then diminished throughout the weeks prior to the childbirth and a clear decrease is seen after the delivery, even though it is still slightly higher than non-pregnant women $[2,8]$. Frequency of murine endometrial Tregs peaks in the estrus phase and then declines during metestrus and remains low until the next estrus [5, 9]. In pregnant mice, Tregs are quickly recruited to uterus draining lymph nodes and are activated during the first 2 days after the implantation [1]. In the early stages of mouse pregnancy, the origin of accumulated Tregs in uterine draining lymph is thymus that will substitute for periphery in later pregnancy stages [10]. The importance of Tregs for successful pregnancy in mice is substantiated by exploiting an adoptive transfer model. In this model, transferring Treg-depleted $\mathrm{T}$ cell population to $\mathrm{nu} / \mathrm{nu} \mathrm{BALB} / \mathrm{c}$ mice led to fetus rejection in allogeneic mating, whereas transferring total $T$ cell population resulted in successful pregnancy [1].

Antigen-dependent and antigen-independent mechanisms contribute to induction of Tregs during pregnancy, resulting in immunological tolerance toward the fetus without endangering the integrity of the mother's immune system. The most important factors that trigger antigen-independent pathway of Tregs induction include estrogen [11], progesterone [12], PGE2 [13], TGF- $\beta$ [14] and IDO. IDO is one of the known inhibitory factors secreted from different cells of the immune system and also MSCs, plays a vital role in pregnancy immune tolerance by metabolizing tryptophan at the maternal-fetal interface [15]. Sufficient amount of IDO in placenta and decidua is necessary to prevent rejection of fetal allograft and maintenance of normal pregnancy $[16,17]$ through induction of Foxp $3^{+}$regulatory T cells [18]. Furthermore, kynurenine as a tryptophan metabolite produced by IDO can suppress the immune system and inhibit $T$ cell proliferation by induction of cell cycle arrest and apoptosis [19].

In human, a sharp increase in the number of Tregs in the follicular phase is strictly associated with high level of serum estradiol (E2) [3], which not only can affect Treg Foxp3 mRNA expression but also can cause elevation of chemokines responsible for recruitment of Treg cells to the uterus. In parallel, progesterone can induce the development of Tregs and suppress the differentiation of Th1 and Th17 cells $[12,20]$. In the antigen-dependent pathway, the role of seminal fluid in keeping antigenic and environmental signals is quite essential [21]. Seminal fluid contains steroid hormones such as testosterone, estrogens and prostaglandin [22] along with TGF-b [23, 24], which induce uterine hypo-responsiveness to sperm alloantigen's through induction of Tregs [21, 25].

Recently, the importance of mesenchymal stem cells in regulation of immune responses in general and Tregs in particular has been highlighted. Several studies have shown the ability of mesenchymal stem cells (MSCs) from different origins in induction of Tregs. BM-MSC is able to inhibit $\mathrm{T}$ cell proliferation and shift $\mathrm{T}$ cell profile toward Tregs $[26,27]$. MSCs from other sources such as those derived from adipose tissue also mediate the generation of Tregs with immunosuppressive ability $[28,29]$. As one of the most regenerative tissues in the human body, the endometrium provides a unique source of adult stromal/stem cells. The immunomodulatory capacity of endometrial stromal/stem cells (eMSCs) has not been fully elucidated. Reportedly, this cell type can inhibit the proliferation of mouse splenocytes stimulated with mitogen [30], and also, it has the capacity to recruit immature dendritic cells by different array of chemokines [31, 32]. eMSC population shed during menstruation into menstrual fluid. Menstrual blood stromal/ stem cells (MenSCs) are newly identified adult stem cells with multi-lineage differentiation capacity [33-38]. In 2008, Murphy et al. proposed the immunomodulatory ability of MenSCs to suppress mixed lymphocyte reaction (MLR) and to attenuate pro-inflammatory responses [39], a finding that was supported by our investigations showing the suppressive effects of MenSCs on allogeneic MLR in a dose-depended manner [40]. These cells share phenotypic and functional properties with other MSCs, yet have their own specificities [41, 42]. Moreover, we 
also reported the potency of these cells to inhibit dendritic cell maturation [43]. In a recent report, we showed that MenSCs are able to modulate functional features of natural killer (NK) cells and induce a pregnancy-friendly phenotype in these cells [44]. Here, we hypothesized that MenSCs contribute to uterine immune system regulation through induction of functionally active regulatory $\mathrm{T}$ cells.

\section{Materials and methods Sample collection}

Menstrual blood was collected from 18 apparently healthy women aging between 25 and 35 years after getting signed inform consent. We were not able to do all experiments on each MenSCs sample because experiments had to be performed on MenSCs with low passage number. Menstrual blood samples did not yield a sufficient number of cells suffice to do all experiments simultaneously. Indeed, doing all experiments at the same time was practically impossible. So, we did a part of the experiments on a set of samples and the rest of experiments with another sets. Nonetheless, not less than six samples were tested in any experiment. Participants had at least one live birth, no history of pregnancy complications including abortion and preeclampsia, no background diseases and no consumption of contraceptive, antiinflammatory drugs, corticosteroids or vitamin D in the last three months before sampling. They also had negative test results for such blood transmittable viruses such as HCV, HBV, and HIV and had no sign or symptoms of endometriosis and autoimmune diseases. Menstrual blood sample collection was performed as we described recently [44] in the second day of menstruation using Diva Cup (Lunette, Stockholm, Sweden) and immediately transported to the laboratory in a cold chain. Bone marrow-derived mesenchymal stem cells (BMSCs) from four healthy donors were obtained from Avicenna Research Institute (ARI) biobank, and buffy coats were collected from Iranian Blood Transfusion Organization (IBTO).

\section{MenSCs isolation and culture}

Isolation of MenSCs was carried out according to the protocol we described recently [45]. In brief, menstrual blood samples were washed and cultured in DMEM/F12 supplemented with penicillin-streptomycin and 10\% fetal bovine serum (FBS) (Gibco, USA). After 48 h., nonadherent cells were removed and MenSCs were allowed to propagate. After confluency of about $80 \%$, cells were detached using trypsin-EDTA (Gibco, USA) and stored at liquid nitrogen. BMSCs were cultured in the same condition as with MenSCs. All experiments were performed on MenSCs and BMSCs at passages below five.

\section{Multi-lineage differentiation and immunophenotyping of MenSCs}

Differentiation of MenSCs toward osteocytes, chondrocyte, and adipocyte was carried out according to the protocols we published elsewhere [37, 38, 45]. Immunophenotype of MSCs was examined by flow cytometry using a panel of antibodies against mesenchymal and embryonic stem cells and hematopoietic cell markers (Table 1). All immunostainings were done by direct staining with fluorochrome-labelled antibodies except for Oct-4 which was done by two-step indirect intracellular staining using rabbit anti-human Oct-4 antibody (Abcam, UK) and FITC-conjugated goat anti-rabbit Ig (Abcam, UK). Signals were analyzed using Attune NxT flow cytometer (Thermo Fisher Scientific, USA) in reference to appropriate isotype controls.

\section{T CD4 + isolation and MenSCs-T CD4 + co-culture}

Peripheral blood mononuclear cells (PBMCs) were isolated from buffy coat using Ficoll-Hypaque density gradient medium (Biosera, USA). Upon harvesting and washing, $\mathrm{CD} 4+\mathrm{T}$ cells were isolated from PBMCs using human T CD4 + cell Isolation kit (Miltenyi Biotec, Germany) according to manufacturer's instruction. Isolated cells had viability and purity of $>95 \%$ as assessed by trypan blue dye exclusion and $\mathrm{CD} 4+$ staining by flow cytometry. For MenSCs-T CD4+ co-culture, $2 \times 10^{5}$ freshly isolated $\mathrm{CD} 4+\mathrm{T}$ cells were co-cultured with

Table 1 Antibody panel for immunophenotyping of MenSCs

\begin{tabular}{|c|c|c|c|}
\hline Antibody & Fluorochrome & Clone & Company \\
\hline Anti-CD9 & FITC & M-L13 & $\begin{array}{l}\text { BD Bio- } \\
\text { sciences }\end{array}$ \\
\hline Anti-CD10 & PE & $\mathrm{H} 110 \mathrm{a}$ & $\begin{array}{l}\text { BD Bio- } \\
\text { sciences }\end{array}$ \\
\hline Anti-CD29 & PE & MAR4 & $\begin{array}{l}\text { BD Bio- } \\
\text { sciences }\end{array}$ \\
\hline Anti-CD34 & FITC & 581 & $\begin{array}{l}\text { BD Bio- } \\
\text { sciences }\end{array}$ \\
\hline Anti-CD38 & FITC & HIT2 & $\begin{array}{l}\text { BD Bio- } \\
\text { sciences }\end{array}$ \\
\hline Anti-CD44 & PE & 515 & $\begin{array}{l}\text { BD Bio- } \\
\text { sciences }\end{array}$ \\
\hline Anti-CD45 & PE & HI30 & $\begin{array}{l}\text { BD Bio- } \\
\text { sciences }\end{array}$ \\
\hline Anti-CD73 & PE & AD2 & $\begin{array}{l}\text { BD Bio- } \\
\text { sciences }\end{array}$ \\
\hline Anti-CD105 & PE & 166707 & $\begin{array}{l}\text { BD Bio- } \\
\text { sciences }\end{array}$ \\
\hline Anti-CD133 & $P E$ & W6B3C1 & $\begin{array}{l}\text { BD Bio- } \\
\text { sciences }\end{array}$ \\
\hline Anti-Oct-4 & - & Polyclonal & Abcam \\
\hline Anti-SSEA-4 & - & MC813-70 & $\begin{array}{l}\text { BD Bio- } \\
\text { sciences }\end{array}$ \\
\hline
\end{tabular}


titrating amounts of MenSCs in 24-well plates (Corning, USA) in a total volume of $1 \mathrm{~mL} /$ well. Culture medium consisted of RPMI-1640 (Gibco, USA) supplemented with penicillin $(100 \mu \mathrm{g} / \mathrm{mL})$, streptomycin $(100 \mathrm{IU} / \mathrm{mL})$, L-glutamine ( $2 \mathrm{mM}$ ) (all from Sigma, USA), non-essential amino acids, sodium pyruvate, and 10\% FBS (all from Gibco, USA). Several different settings were tested in MenSCs-T CD4 + co-culture. In one setting, MenSCs were remained untreated or mitotically inactivated with $25 \mu \mathrm{g} / \mathrm{mL}$ of Mitomycin C (Sigma, USA) for $1 \mathrm{~h}$. before co-culturing. In parallel, to verify the effect of IFN- $\gamma$ and/ or IL-1 $\beta$ on MenSCs function, MenSCs were treated with either $25 \mathrm{ng} / \mathrm{mL}$ IFN- $\gamma$ (BD Biosciences, USA) and/ or $10 \mathrm{ng} / \mathrm{mL}$ IL-1 $\beta$ (BD Biosciences, USA) $48 \mathrm{~h}$. prior to co-culture with $\mathrm{T} C \mathrm{CD} 4+$ cells. At initiation of the co-culture, $\mathrm{T}$ cells were activated with activation beads containing $5 \mu \mathrm{g} / \mathrm{mL}$ anti-CD3 and $5 \mu \mathrm{g} / \mathrm{mL}$ anti-CD28 at 4:1 ratio (CD4 $+\mathrm{T}$ cell to bead) according to manufacturer's instruction (Miltenyi Biotec, Germany). In the third day of co-culture, half of the culture media was gently replaced with fresh RPMI-1640, containing $100 \mathrm{U} / \mathrm{mL}$ recombinant IL-2 (R\&D systems, USA). In most settings, BMSCs were co-cultures in parallel.

\section{Measurement of IDO activity}

A colorimetric method was used to determine the activity of IDO in MenSCs and BMSCs. MenSCs were treated with $100 \mathrm{ng} / \mathrm{mL}$ IFN- $\gamma$ (BD Biosciences, USA) in the presence or absence of $10 \mathrm{ng} / \mathrm{mL}$ IL-1 $\beta$ (BD Biosciences, USA) or remained untreated. Similarly, BMSCs were treated with IFN- $\gamma$ or remained untreated as a control. Untreated cells or those treated with $100 \mathrm{ug} / \mathrm{mL}$ L-Tryptophan (Trp) served as controls. The activity of IDO was measured as described earlier [46].

\section{Proliferation assay and Treg generation}

To assess the effects of MenSCs on CD4 + T cells proliferation, $\mathrm{CD} 4+\mathrm{T}$ cells were co-cultured in different settings as mentioned above. Before co-culturing, CD4 $+\mathrm{T}$ cells were washed and labeled with $5 \mu \mathrm{M}$ 5,6-carboxyfluorescein diacetate succinimidyl ester (CFSE) (Molecular Probes, USA).

To investigate the effects of MenSCs secretome on $\mathrm{CD} 4+\mathrm{T}$ cell proliferation, a transwell system (Corning, USA) was utilized. Briefly, IFN- $\gamma / \mathrm{IL}-1 \beta$-treated MenSCs were seeded in the lower chamber of a 24-well transwell plate. Later, $\mathrm{CD} 4+\mathrm{T}$ cells were added into the upper chamber and plates were incubated for five days in incubator. In some settings, $1 \mathrm{mM} 1$-MethylDL-tryptophan (Sigma, USA) as IDO blocker, $20 \mathrm{mM}$ Indomethacin (Sigma, USA) as PGE2 inhibitor, $10 \mu \mathrm{g} /$ $\mathrm{mL}$ anti-IL-6 antibody (R\&D systems, USA), $10 \mu \mathrm{g} / \mathrm{mL}$ anti-IL10 antibody (R\&D systems, USA) or $10 \mu \mathrm{g} / \mathrm{mL}$
anti-TGF- $\beta$ (R\&D systems, USA) were added to the cocultures in order to investigate the involvement of aforesaid molecules on modulatory effects of MenSCs on T cell proliferation or Treg generation. After 5 days, proliferation of CD4 $+\mathrm{T}$ cells and frequency of Tregs were assessed by flow cytometry.

\section{Isolation of Tregs and functional assays}

To investigate the percentage and functional properties of Tregs induced by co-culture of CD $4+\mathrm{T}$ cells with MenSCs, Treg cells were isolated from 5-day cocultures by Treg isolation kit (Miltenyi Biotec, Germany) according to manufacturer's instruction, and their functional property to inhibit stimulated PBMCs was assessed. For this purpose, PBMCs autologous to the Tregs were first stained with CFSE and added to the wells of 96-well $U$ bottom plates (Corning, USA) $\left(5 \times 10^{4}\right.$ cells $/$ well $\left./ 50 \mu \mathrm{L}\right)$. Isolated Treg cells were then added to the wells at the ratios of 1:5 and 1:10 (Treg to PBMCs) in a volume of $50 \mu \mathrm{L} /$ well. Finally, activation/ expansion beads (Miltenyi Biotec, Germany) containing $5 \mu \mathrm{g} / \mathrm{mL}$ anti-CD3 and $5 \mu \mathrm{g} / \mathrm{mL}$ anti-CD28 at $1: 2$ ratio (bead to PBMC) were added to the wells, and total volume of each well was adjusted to $200 \mu \mathrm{L}$. In the second day of culture, $100 \mu \mathrm{L}$ of culture medium was gently replaced with fresh culture medium containing $200 \mathrm{U} /$ mL IL-2 (R\&D systems, USA) and incubation was continued for 2 days at \%CO2 incubator. Proliferation of PBMCs was then measured by flow cytometry.

\section{Flow cytometry}

Flow cytometry experiments were performed to assess $\mathrm{T}$ cells co-cultured with MenSCs. The fluorochromeconjugated antibodies included Alexa Fluor 647 antiFoxP3 (BD Biosciences, USA), FITC anti-human IFN- $\gamma$, PerCP/Cy5.5 anti-CD4, APC anti-human IL-10, and PE anti-CD25 (All from Biolegend, USA) were employed. Antibodies were used at the concentrations recommended by the manufacturers. For assessment of cytokines, cells were treated with $50 \mu \mathrm{g} / \mathrm{mL}$ PMA (Sigma, USA), $1 \mu \mathrm{g} / \mathrm{mL}$ ionomycin (Sigma, USA) and $0.7 \mu \mathrm{g} / \mathrm{mL}$ Monensin (BD Biosciences, USA) $6 \mathrm{~h}$. before staining procedure. For intracellular staining of Foxp3 and cytokines, transcription factor buffer set (BD Biosciences, USA) was used for cell permeabilization and fixation according to the manufacturer's instruction. Cells were also stained with Live/Dead fixable near red fluorescent dye (Molecular Probes, USA) to separate the alive and dead populations before antibody-specific gating. The stained cell was then read by flow cytometer Attune NxT flow cytometer and analyzed by FlowJo software (FlowJo, LLC, USA). 


\section{Statistics}

All statistical analyses and group comparisons were performed using GraphPad Prism 8. Data were compared with the Mann-Whitney test. Descriptive data were reported as mean \pm standard error of the mean (SEM). $P$ values less than 0.0332 were interpreted as statistically significant. P values less than $0.0332,0.0021,0.0002$, and 0.0001 were shown as $*$, **,***, and ${ }^{* * * * *}$, respectively.

\section{Results}

\section{Workflow of the experimental design}

Figure 1 depicts the workflow of the experimental design used in this study.

\section{Characterization of MenSCs}

MenSCs isolated from menstrual blood were characterized by multi-lineage differentiation and immunophenotyping. A considerable fraction of MenSCs were able to differentiate toward osteocyte, chondrocyte and adipocyte, as judged by specific stainings (Additional file 1: Fig. S1A). Cells grown in the absence of induction media failed to differentiate. MenSCs expressed markers of mesenchymal origin, but failed to express hematopoietic-specific markers. Unlike BMSCs, MenSCs expressed Oct-4 but were negative for SSEA-4 (Additional file 1: Fig. S1B). The results obtained here were almost the same with those we reported earlier [44, 47].

\section{Pro-inflammatory cytokines are needed to induce inhibitory capacity of MenSCs on T cell proliferation}

The capacity of MenSCs to modulate CD4 $+\mathrm{T}$ cell proliferation was tested at different conditions by flow cytometry. First, the impact of Mitomycin $\mathrm{C}$ and IFN- $\gamma$ treatment of MenSCs on T cell proliferation was assessed. Untreated MenSCs were shown to increase the proliferation of $\mathrm{CD} 4+\mathrm{T}$ cells compared to $\mathrm{CD} 4+\mathrm{T}$ cells cultured alone $(p<0.0002)$. Mitomycin $C$ inactivation of MenSCs had no effect on increased proliferation of CD4+ T cells co-cultured with MenSCs. IFN- $\gamma$ treatment of MenSCs decreased their capacity to induce T cell proliferation compared to untreated MenSCs $(p<0.0332)$ (Fig. 2B). Expectedly, IFN- $\gamma$-treated BMSCs strongly

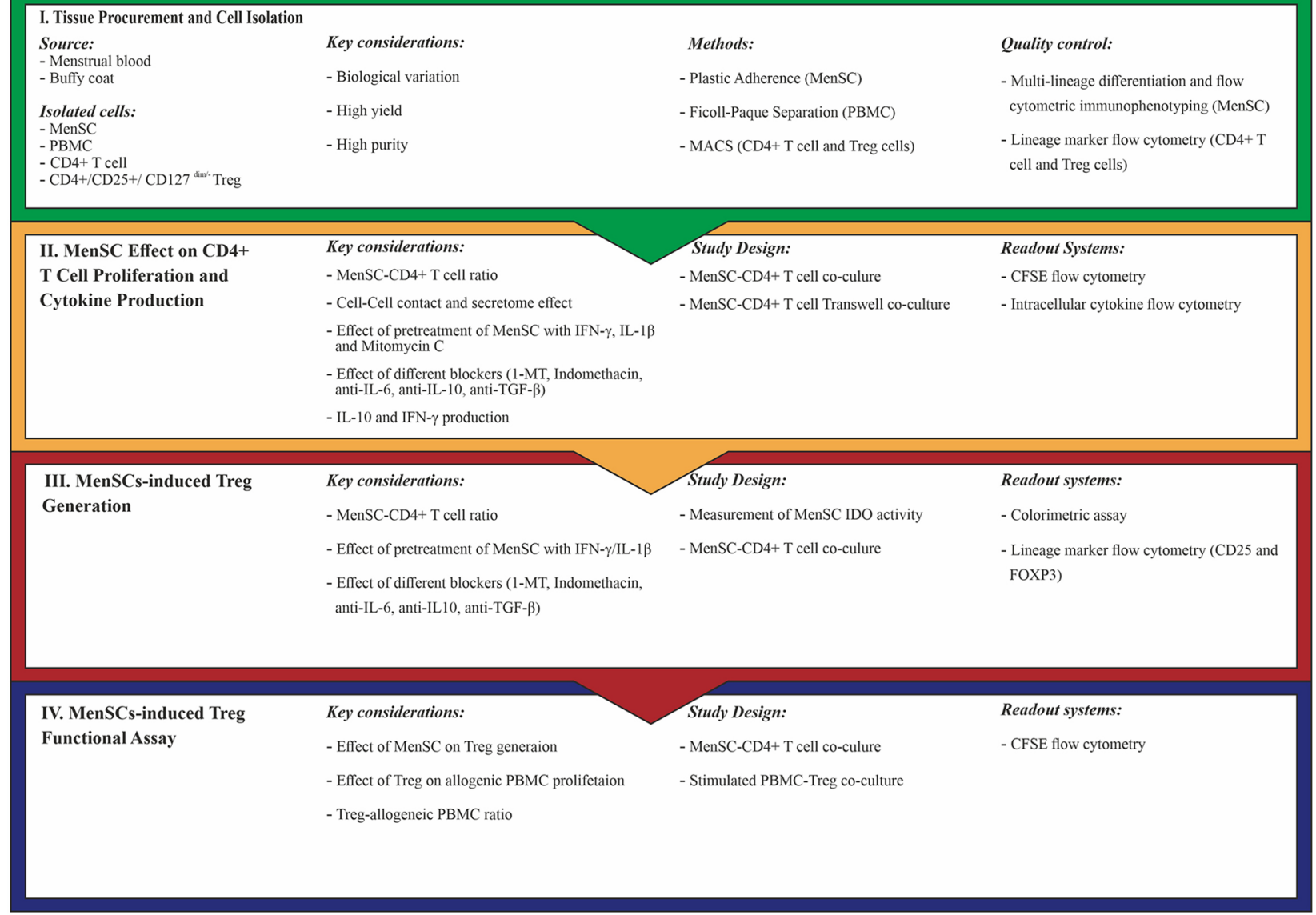

- PBMC $\quad$ - High purity

Key considerations:

- Biological variation

- High yield

CD4+/CD25+/CD127 ${ }^{\text {dink }}$ Treg

Methods:

- Plastic Adherence (MenSC)

- Ficoll-Paque Separation (PBMC)

- MACS (CD4+ T cell and Treg cells)

Quality control:

- Multi-lineage differentiation and flow cytometric immunophenotyping (MenSC)

- Lineage marker flow cytometry $(\mathrm{CD} 4+\mathrm{T}$ cell and Treg cells)

\begin{tabular}{|lll}
\hline II. MenSC Effect on CD4+ & Key considerations: & Study Design: \\
T Cell Proliferation and & - MenSC-CD4+ T cell ratio & - MenSC-CD4+ T cell co-culure \\
Cytokine Production & - Cell-Cell contact and secretome effect & - MenSC-CD4+ T cell Transwell co-culture \\
& - Effect of pretreatment of MenSC with IFN- $\gamma$, IL-1 $\beta$ & - Intracellular cytokine flow cytometry \\
and Mitomycin C & \\
- Effect of different blockers (1-MT, Indomethacin, \\
anti-IL-6, anti-IL-10, anti-TGF- $\beta$ ) \\
- IL-10 and IFN- $\gamma$ production
\end{tabular}

\begin{tabular}{|c|c|c|c|}
\hline \multirow{4}{*}{$\begin{array}{l}\text { III. MenSCs-induced Treg } \\
\text { Generation }\end{array}$} & Key considerations: & Idy Design: & Readout systems: \\
\hline & - MenSC-CD4+ T cell ratio & - Measurement of MenSC IDO activity & - Colorimetric assay \\
\hline & - Effect of pretreatment of MenSC with IFN- $\gamma / \mathrm{IL}-1 \beta$ & - MenSC-CD4+ T cell co-culure & - Lineage marker flow cytometry (CD25 and \\
\hline & $\begin{array}{l}\text { - Effect of different blockers (1-MT, Indomethacin, } \\
\text { anti-IL-6, anti-IL10, anti-TGF- } \beta \text { ) }\end{array}$ & & FOXP3) \\
\hline \multirow{4}{*}{$\begin{array}{l}\text { IV. MenSCs-induced Treg } \\
\text { Functional Assay }\end{array}$} & Key considerations: & . & Readout systems: \\
\hline & - Effect of MenSC on Treg generaion & - MenSC-CD4+ T cell co-culure & - CFSE flow cytometry \\
\hline & - Effect of Treg on allogenic PBMC prolifetaion & - Stimulated PBMC-Treg co-culture & \\
\hline & - Treg-allogeneic PBMC ratio & & \\
\hline
\end{tabular}

Fig. 1 Workflow of the experimental design 


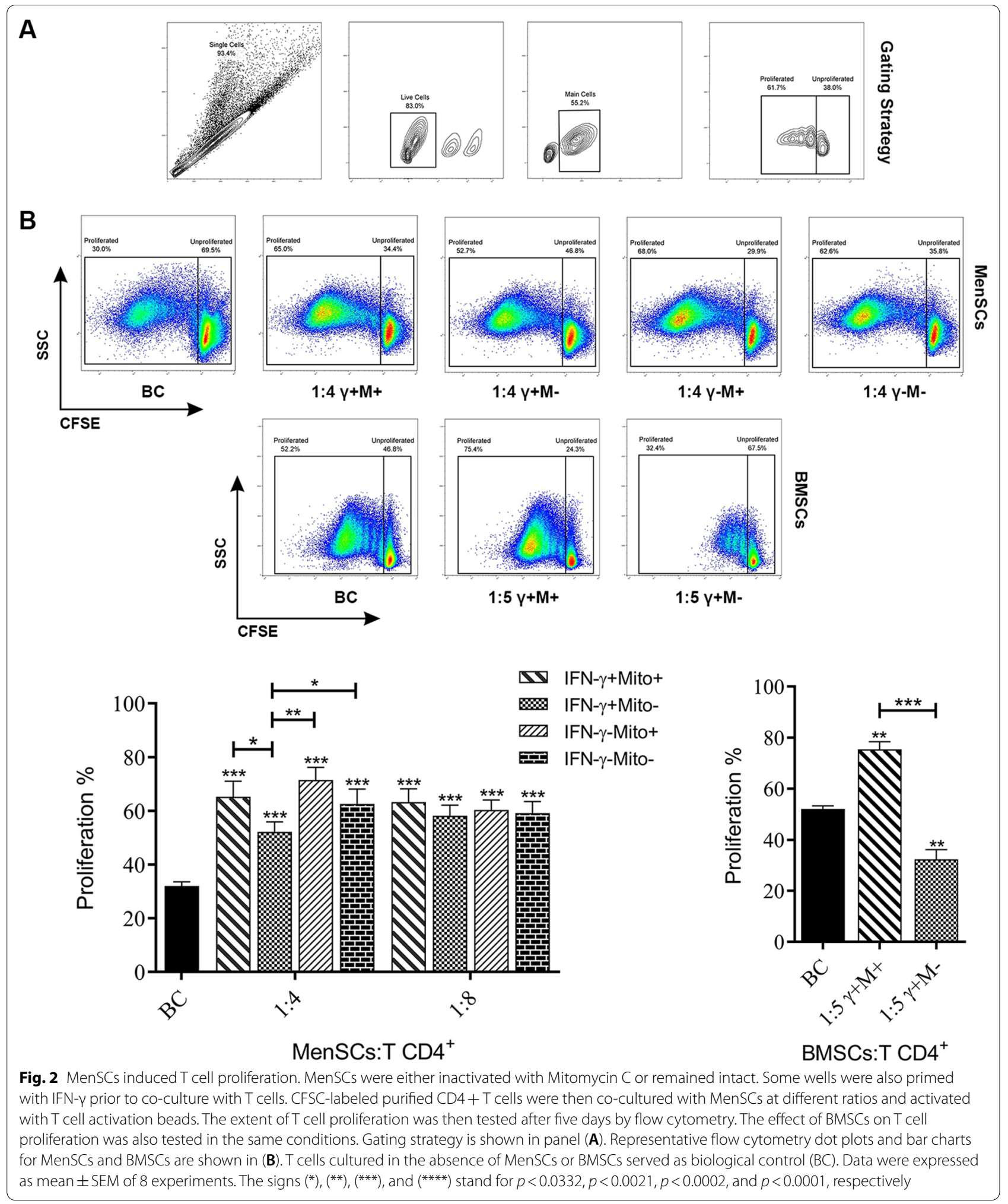


inhibited $\mathrm{T}$ cell proliferation $(p<0.0021)$. However, the inactivation of BMSCs with Mitomycin C prior to IFN$\gamma$-treatment reversed this effect and caused significant $T$ cell proliferation $(p<0.0021)$. Based on these findings, all subsequent tests were done without Mitomycin treatment. Next, we tested the effect of MenSCs on CD4+ T cells proliferation at different ratios. As with our earlier report [48], we observed that MenSCs significantly promoted $\mathrm{T}$ cell proliferation compared to the biological control at $1: 2-1: 8$ ratios $(p<0.0002-0.0001)$ (Fig. 3A). Regarding the simultaneous presence of multiple proinflammatory cytokines in early pregnancy decidua, the effect of simultaneous treatment of MenSCs with IFN- $\gamma$ and IL- $1 \beta$ on T cell proliferation was tested at the next

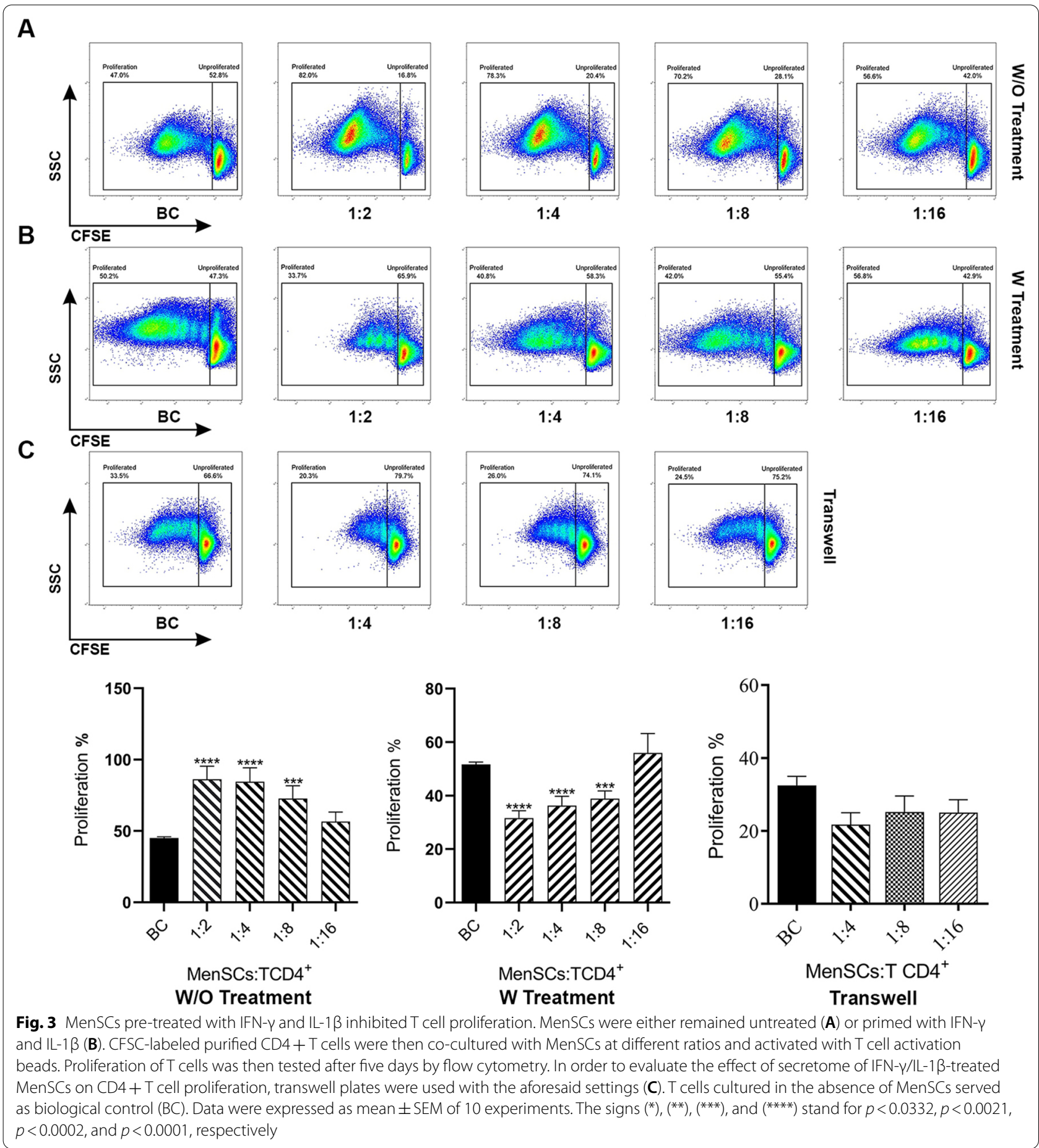


step. As depicted in Fig. 3B, simultaneous treatment of MenSCs with IFN- $\gamma$ and IL- $1 \beta$ inhibited the proliferation of $\mathrm{CD} 4+\mathrm{T}$ lymphocytes compared to the biological control $(p<0.0002-0.0001)$ at 1:2-1:8 ratios. In order to evaluate the effect of IFN- $\gamma$ - and IL- $1 \beta$-treated MenSCs on the proliferation of $\mathrm{CD} 4+\mathrm{T}$ lymphocytes without cell-cell contact, transwell plates were used. As shown in Fig. $3 \mathrm{C}$, although the proliferation of CD4+ T cells in the absence of cell-cell contacts was inhibited, the differences were not significant.

\section{Inhibition of PGE2 and IDO increased the proliferation of $\mathrm{CD} 4+\mathrm{T}$ cells}

To explore the mediators responsible for inhibition of $\mathrm{T}$ cell proliferation by pre-treated MenSCs, different blockers including anti-IL-6, anti-IL-10, anti-TGF- $\beta$, indomethacin, 1 methyl tryptophan $(1 \mathrm{MT})$ or their double combinations were added to the MenSCs-T cell co-cultures at 1:8 ratio. Untreated MenSCs and MenSCs treated with IFN $-\gamma$ and IL- $1 \beta$ served as untreated and treated controls, respectively. As illustrated in Fig. 4A, anti-IL-6, anti-IL-10, and combination of anti-IL-10 and anti-TGF- $\beta$ failed to restore $\mathrm{T}$ cell proliferation. In contrary, treatment of MenSCs with indomethacin or double combination of indomethacin and 1-MT significantly restored $\mathrm{T}$ cell proliferation to the level observed in the treated control $(\mathrm{p}<0.0002)$.

\section{IFN- $\gamma / \mathrm{IL}-1 \beta$-treated MenSCs induced IL-10 and IFN- $\gamma$ production in $\mathrm{CD} 4+\mathrm{T}$ cells}

To see how MenSCs affect the balance of TH1/TH2, the levels of intracellular IL-10 and IFN- $\gamma$ were measured in $\mathrm{CD} 4+\mathrm{T}$ cells after co-culture with MenSCs at 1:8 ratio (MenSCs:CD4+ T cells). As shown in Fig. 4C, MenSCs

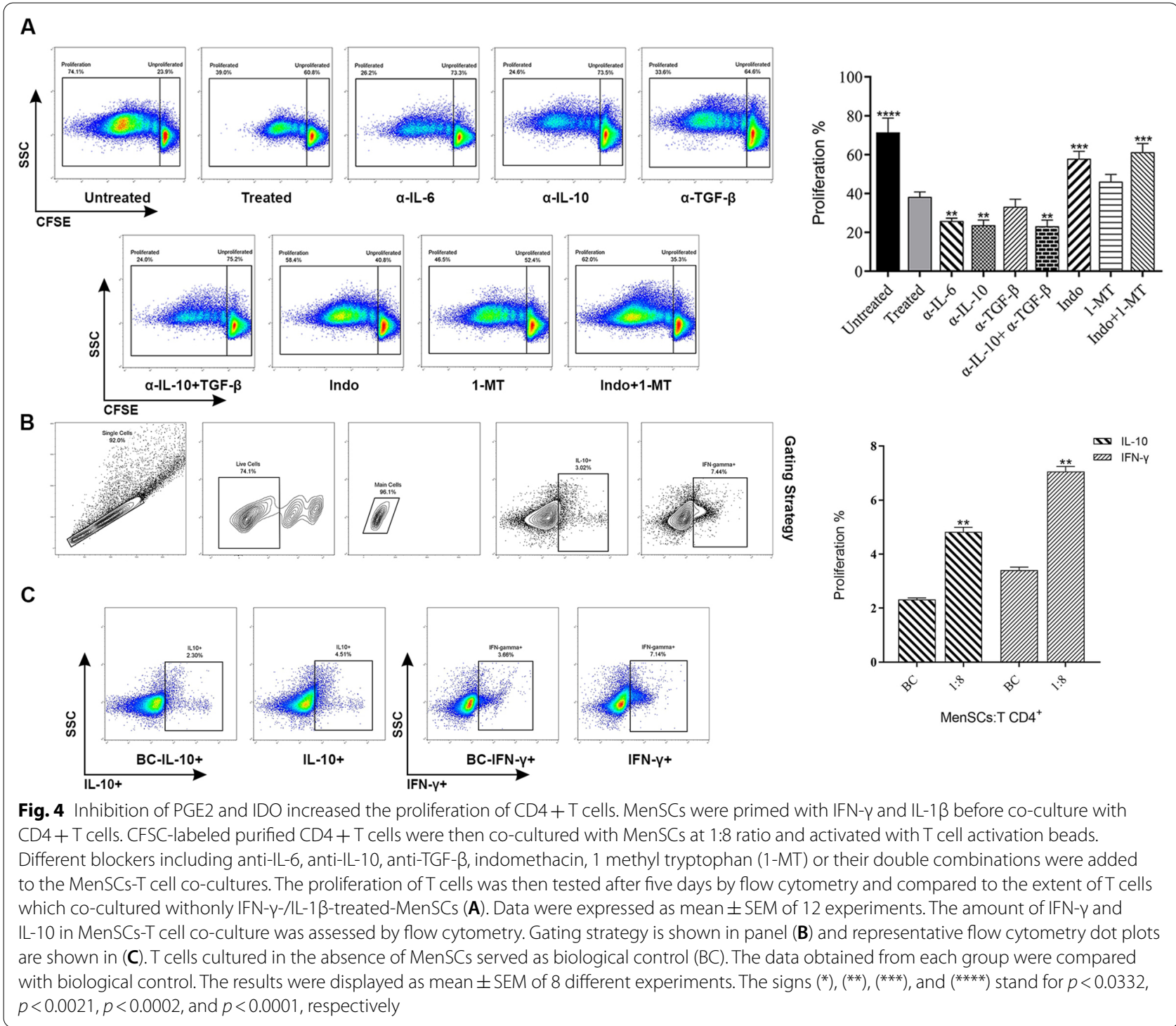


significantly $(p<0.0021)$ increased the production of both cytokines in $\mathrm{CD} 4+\mathrm{T}$ lymphocytes.

\section{MenSCs treated with IFN- $\gamma$ - and IL- $1 \beta$-induced Tregs}

In the next step, the effect of untreated MenSCs on induction of Tregs was examined. $T$ cells cultured alone served as biological control. As shown in Fig. 5B, untreated MenSCs decreased the frequency of Tregs at $1: 4$ and $1: 8$ co-culture ratios $(p<0.0002)$. The mean percentage of Tregs decreased from $(3.21 \pm 0.05)$ to $(2.16 \pm 0.24)$ and $(2.49 \pm 0.15)$ when $\mathrm{T}$ cells were cocultured with untreated MenSCs at 1:4 and 1:8 ratios, respectively. Based on the results presented above, the effect of IFN- $\gamma$ and IL-1 $\beta$ treatment of MenSCs on
A
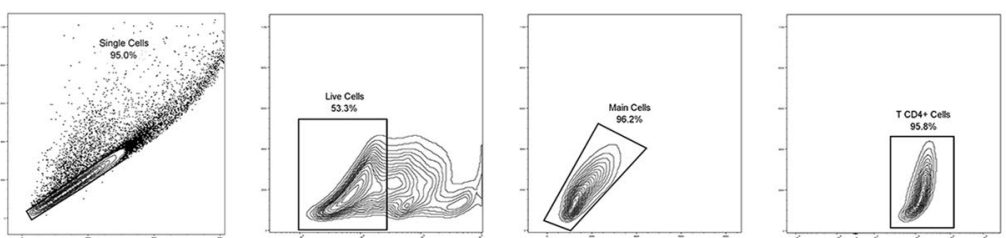

B

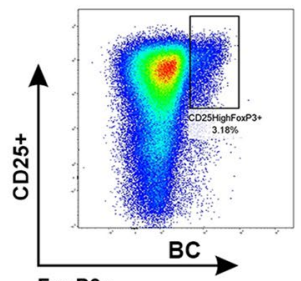

C

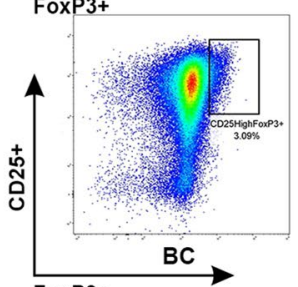

D

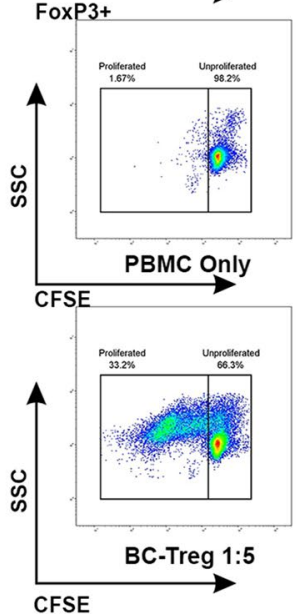

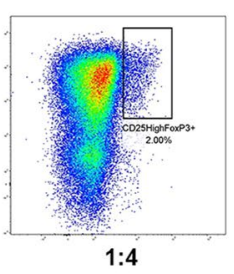

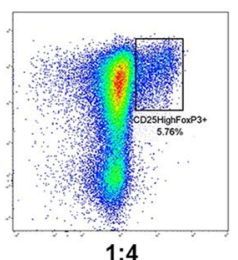

$1: 4$

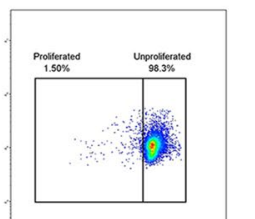

BC-Treg

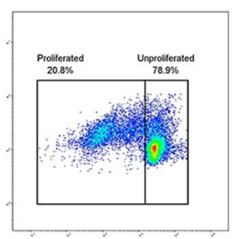

MenSCs-Treg 1:5

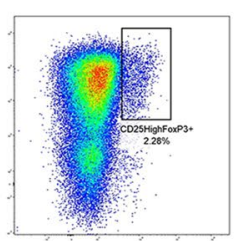

$1: 8$

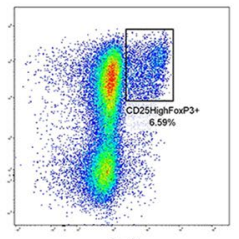

$1: 8$

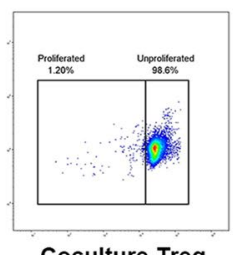

Coculture-Treg

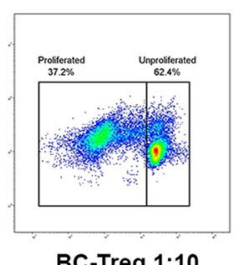

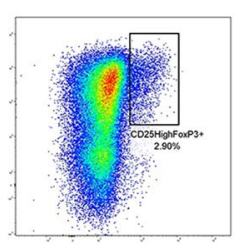

$1: 16$

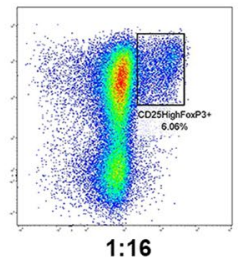

$1: 16$

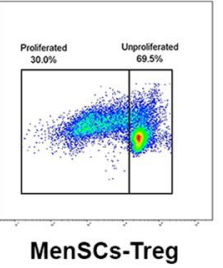

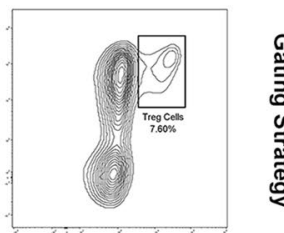
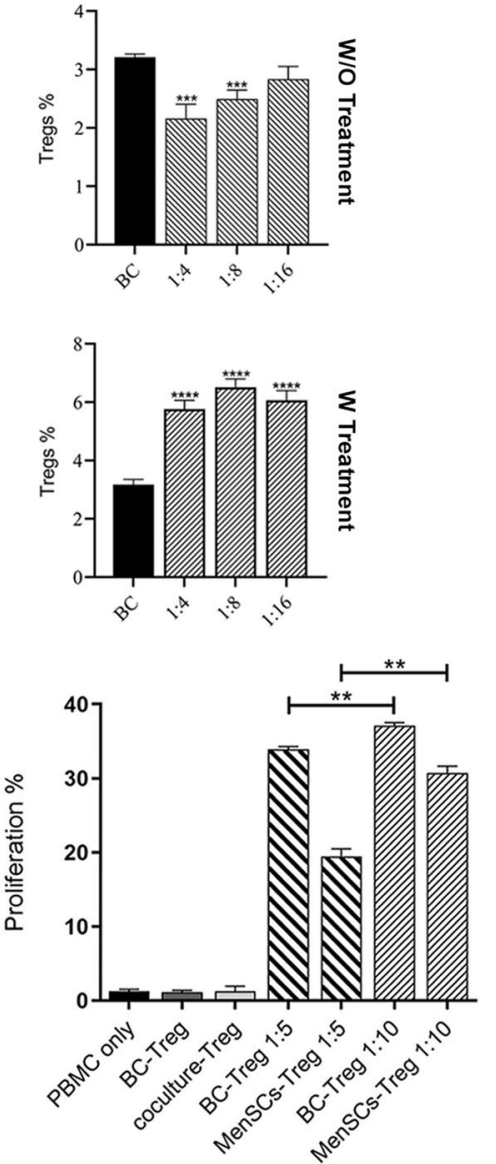

Fig. 5 MenSCs pre-treated with IFN- $\gamma$ - and IL-1 $\beta$-augmented functional Treg generation. Purified CD4+T cells were co-cultured with MenSCs at different ratios and activated with T cell activation beads. After five days, percent of CD4 + CD25 ${ }^{\text {high }}$ FOXP3 + Tregs was quantified by flow cytometry. Gating strategy for Tregs is shown in panel (A). MenSCs were either remained untreated (B) or primed with IFN- $\gamma$ and IL-1 $\beta$ (C). T cells cultured in the absence of MenSCs served as biological control (BC). The data obtained from each group were compared with biological control, and the data were expressed as mean \pm SEM of 12 experiments. IL-1 $\beta /$ IFN- $\gamma$-treated MenSCs were co-cultured with CD4 + T cells for five days and induced Tregs were then isolated by MACS. Tregs were added at 1:5 and 1:10 ratio to the CFSC-labeled autologous PBMCs cultures activated with activation beads and proliferation of PBMCs were measured after 4 days by flow cytometry (D). Wells containing single PBMCs, Tregs (generated in the absence of MenSCs, BC-Treg), or MenSCs-induced Tregs (Coculture-Treg) served as negative controls. Co-cultures containing Tregs (generated in the absence of MenSCs) and PBMCs at ratio of 1:5 and 1:10 were considered as positive control. Results were displayed as Mean \pm SEM of 6 different experiments. The signs $\left(^{* *}\right)$ and $\left({ }^{* *}\right)$ stand for $p<0.0021$ and $p<0.0002$, respectively 
induction of Tregs was tested in the next step. As shown in Fig. $5 \mathrm{C}$, MenSCs treated with IFN- $\gamma$ and IL- $1 \beta$ significantly augmented Treg frequency at all co-culture ratios tested $(p<0.0001)$. The percentage of Tregs increased twofold when T cells were co-cultured with MenSCs pretreated with pro-inflammatory cytokines.

\section{MenSCs-induced Tregs were functionally active to inhibit PBMC proliferation}

Functional properties of Tregs generated in the presence of MenSCs were tested by inhibition of PBMCs proliferation. Wells containing single PBMCs, Tregs (generated in the absence of MenSCs), or MenSC-induced Tregs served as negative controls. Co-cultures containing Tregs (generated in the absence of MenSCs) and PBMCs were considered as positive control. Tregs were added at 1:5 and 1:10 ratio to the CFSC-labeled PBMC cultures activated with activation beads. All control wells showed only a negligible level of cell proliferation. As shown in Fig. 5D, MenSC-induced Tregs were able to significantly $(p<0.0021)$ inhibit the proliferation of PBMCs in both 1:5 and 1:10 ratios with a mean percentage of $19.50 \pm 0.98$ and $30.73 \pm 0.89$ compared to positive control groups $33.90 \pm 0.40$ and $37.1 \pm 0.40$, respectively.

\section{Blocking of IL-6, IL-10 and TGF- $\beta$ decreased MenSCs ability to induce Tregs}

To find the cytokines involved in the induction of Tregs after co-culture with IFN- $\gamma$-/IL- $1 \beta$-treated MenSCs, co-cultures at 1:8 ratios (MenSCs:CD4 $+\mathrm{T}$ cells) were treated with blocking antibodies against IL-6, IL-10, TGF- $\beta$, as well as indomethacin or 1-MT to inhibit PGE2 and IDO, respectively. Differentiation of CD4 $+\mathrm{T}$ cells toward Tregs in each group was compared to the control group containing the same co-culture without blocking agents. As illustrated in Fig. 6A and B, treatment with blocking antibodies against IL- 6 , IL-10, and TGF- $\beta$ or 1 -MT significantly decreased the percentage of Tregs $(3.06 \pm 0.35, \quad 2.65 \pm 0.38, \quad 2.91 \pm 0.40$, and $3.40 \pm 0.42$, respectively, vs. $4.34 \pm 0.14$ in biological control group) $(p<0.0021)$. Co-treatment with anti-IL-10 and antiTGF- $\beta$ further decreased the percentage of Tregs $(2.07 \pm 0.33, p<0.0002)$. However, inhibition of PGE2 did not affect Treg induction. Further, co-treatment with both indomethacin and 1-MT blockers had no significant effect on the induction of Tregs.

\section{Pre-treatment of MenSCs with inflammatory cytokines induced IDO activity}

To study the activity of IDO secreted by MenSCs, these cells were pre-stimulated with IFN- $\gamma$ as a potent inducer of IDO. We observed that the treatment of MenSCs with IFN- $\gamma$ and IL-1 $\beta$ or IFN- $\gamma$ alone could induce IDO activity $(p<0.0001)$ (Fig. 6C). Treatment of MenSCs with IL- $1 \beta$ alone did not induce IDO activity in these cells. As expected, IFN- $\gamma$-treated BMSCs produced a considerable amount of active IDO. Untreated cells or those treated with tryptophan did not exert a significant IDO activity.

\section{Discussion}

Despite tremendous effort to unravel the immunology of reproduction in species with hemochorial placentation, the mystery of uterus as being a privileged site during pregnancy has not been resolved yet. Several hypotheses have been put forth so far and a dozen of mediators with immunosuppressive properties have been introduced to explain the state of uterine immune system hypo-responsiveness during pregnancy [4]. Nonetheless, with a closer view to the pathways and networks proposed in this regard, it became clear that many of them are interconnected and failure or dysfunction in one pathway might affect the proper functioning of the other pathways. Up to now, it remained unclear which component in the uterus is the main trigger of the delicate uterine immune regulatory network during pregnancy.

In recent years, the central role of mesenchymal stem cells in regulation of immune responses has been highlighted. BM-MSCs have been proved to exert an array of immune regulatory activities including inhibition of $\mathrm{T}$ cell proliferation and skewing $\mathrm{T}$ cell profile toward Tregs [26, 27]. MSCs from other sources such as those derived from adipose tissue also mediate generation of Tregs with immunosuppressive ability $[28,29]$. Human endometrium is a dynamic tissue with ability for hundreds of cycles of growth, differentiation, and shedding during reproductive age. It contains a population of mesenchymal stem/stromal cell (eMSC) which shed during menstruation. While eMSC and MenSCs have several biological features with BM-MSCs, they also show some differences in immunophenotype, functional aspects, and differentiation capacities [49]. We recently showed that MenSCs are able to inhibit functional features of NK cells and TH17 differentiation to exert a pregnancy-friendly phenotype in this cell population [44, 47]. Here we were about to explore how biological features of Tregs, as the central cells in pregnancy tolerance, are affected by MenSCs.

We observed that MenSCs promoted the proliferation of $\mathrm{CD} 4+\mathrm{T}$ cells in a dose-dependent manner. This results were in line with proliferation-promoting effect of MenSCs on NK and T cells [44, 48]. In our previous study, using protein microarray, we showed that MenSCs condition media contained considerably lower level of IGFBP1-4 (Insulin-like growth factor-binding protein) compared to BMSCs, leaving higher functional free form of IGFs to exert trophic activity [44]. We showed 


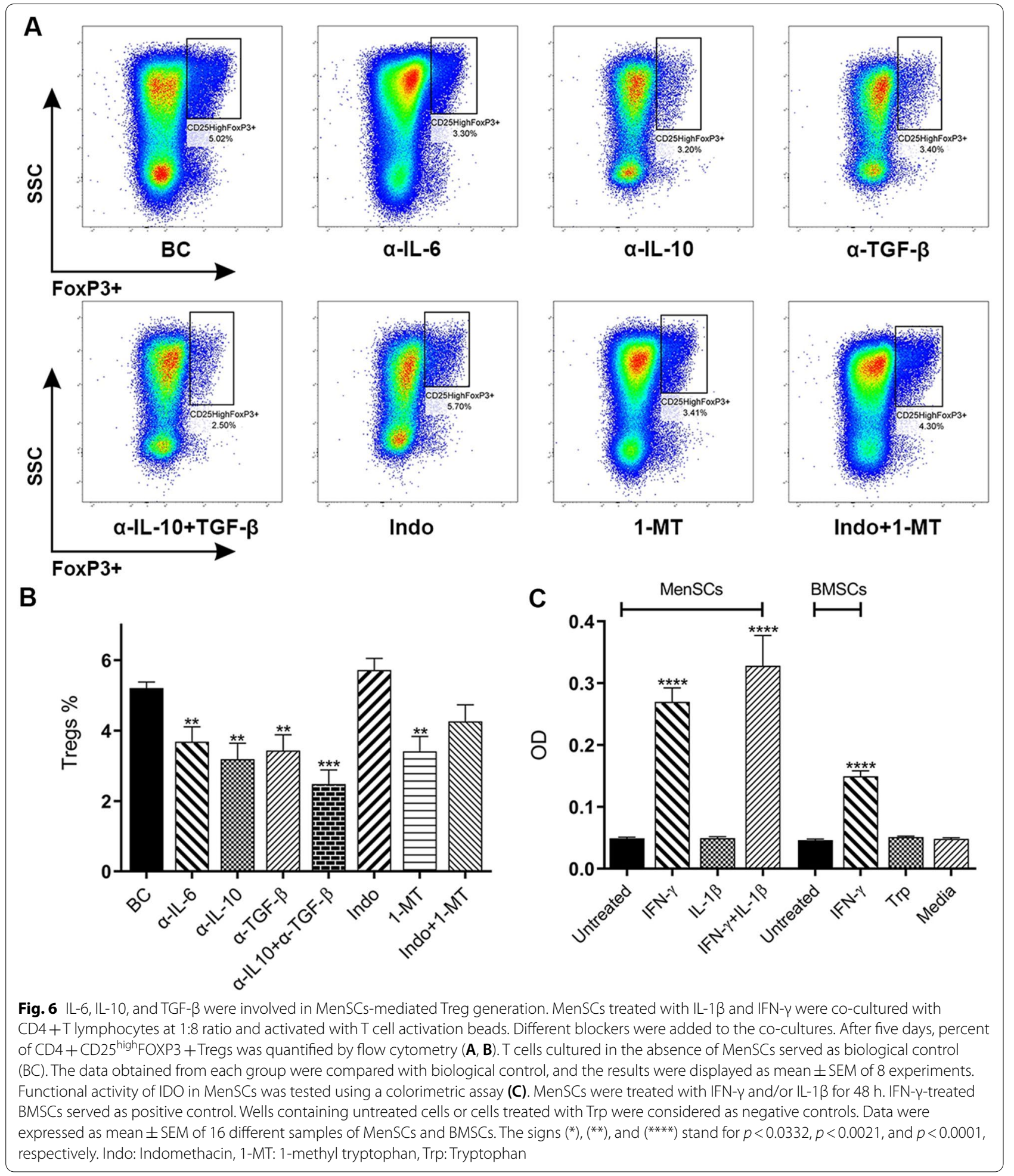

that blocking of IL-6 in the co-culture system resulted in reduced proliferation of $\mathrm{T}$ cells indicating supportive role of this cytokine for T cell proliferation. IL- 6 has been shown to have a particular role in survival of resting [50] and activated $\mathrm{T}$ cells by preventing apoptosis in these cells through a mechanism, which is completely independent of IL-2 [51]. 
Several molecules have been reported to be involved in MSC-mediated immunoregulation. In this regard, proinflammatory cytokines exert a substantial role. IFN- $\gamma$ alone or in combination with other pro-inflammatory cytokines such as TNF- $\alpha$, IL- $1 \alpha$, or IL- $1 \beta$ have profound effects on stimulation of immunoregulatory phenotype in MSC $[52,53]$. Therefore, in the next step we examined the potential effect of pro-inflammatory cytokines on MenSCs-induced $\mathrm{T}$ cell proliferation. We observed that IFN- $\gamma$ treatment alone did not prevent the proliferation of $\mathrm{T}$ cells. However, combinational treatment of MenSCs with IFN- $\gamma / \mathrm{IL}-1 \beta$ significantly reduced $\mathrm{T}$ cell proliferation. It was demonstrated that human embryonic stem cell-derived mesenchymal stromal cells (hES-MSCs) have no significant effect on lymphocyte proliferation despite pre-treatment with IFN- $\gamma$ [54]. Depending on IFN- $\gamma$ dose, umbilical cord blood mesenchymal stem cells have been reported to induce or suppress allogenic lymphocytes after pre-treatment with IFN- $\gamma$ [55]. Responsiveness to pro-inflammatory cytokine treatment is largely dependent on MSC source. We showed that pre-treatment of BMSCs with the same concentration of IFN $-\gamma$ resulted in substantially reduced $\mathrm{T}$ cell proliferation. Recent studies show that compared to BMSCs, MenSCs are less responsive to IFN- $\gamma$ due to fewer expression of IFN- $\gamma$ R1 and IFN- $\gamma$ R2 [53]. Some studies show that adipose-derived stem cells (ASCs) could gain promoted inhibitory properties in the presence of IFN- $\gamma$, IL-1 $\beta$, TNF- $\alpha$, and IFN- $\alpha$ [56]. Our results showed that MenSCs have to be pretreated with both IFN- $\gamma$ and IL- $1 \beta$ to gain the capacity to suppress $\mathrm{T}$ cell proliferation. We also showed that, in contrast to conventional co-culture system, MenSCs pretreated with IFN- $\gamma / \mathrm{IL}-1 \beta$ did not significantly suppress $\mathrm{T}$ cell proliferation in a transwell system. Reportedly, IFN- $\gamma$ along with TNF- $\alpha$ or IL- $1 \beta$ increased ICAM- 1 and VCAM-1 expression and strengthened the attachment of MSCs and T cells in co-culture. Inhibition of these two molecules led to decreased suppressive effects of MSCs $[57,58]$. In this regard, it seems that cell-cell contact plays a significant role in the inhibitory function of IFN- $\gamma /$ IL-1 $\beta$-treated MenSCs on T cell proliferation.

To investigate factors contributed in MenSC-induced suppression of $\mathrm{T}$ cell proliferation following IFN- $\gamma / \mathrm{IL}-1 \beta$ treatment, IL-6, IL-10, TGF- $\beta$, PGE2 and IDO were blocked. We found that PGE2 was involved in suppression of $\mathrm{T}$ cell proliferation in co-culture system. PGE2 is a crucial player in chronic inflammation and could influence the functions of DC, NK and lymphocytes. High concentrations of PGE2 inhibit T lymphocyte proliferation through reducing both IL-2 and IL-2 receptor synthesis [59]. It is also shown that the inhibition of PGE2 reduced the immunosuppressive effects of human cord blood-derived mesenchymal stem cells (CB-MSCs) on
T lymphocytes proliferation [60]. Simultaneous pretreatment of MenSCs with IFN- $\gamma$ and IL- $1 \beta$ resulted in increased expression of COX-2 [53]. Moreover, IFN- $\gamma$ and IL-1 $\beta$ are well-known inducers of PGE2 because both of them can stimulate COX-2 mRNA expression [61, 62]. Inhibition of IDO had not a significant effect on $\mathrm{T}$ cell proliferation. This datum is in line with Gieske et al. that reported anti-proliferative properties of human multipotent mesenchymal stromal cells (MSCs) are independence of IDO [63]. Similarly, inhibition of TGF- $\beta$ alone showed a negligible effect on the proliferation of cocultured CD4 $+\mathrm{T}$ cells. This finding is in line with what reported earlier for umbilical cord MSCs [61]. However, we showed simultaneous inhibition of IL-10 and TGF- $\beta$ or inhibition of IL-10 alone could significantly reduce the proliferation of CD4 $+\mathrm{T}$ cells. In this regard, Harizi and Gualde reported that IL-10 can inhibit COX-2 expression at mRNA and protein levels, which leads to inhibition of PGE2 production in BMDC (bone marrow-derived DC) [64]. As mentioned above, PGE2 plays a pivotal role in suppressive activity of MSCs, therefore by blocking IL-10, PGE2 production could be enhanced leading to further suppression of $\mathrm{T}$ cell proliferation. Nonetheless, based on the complex nature of in vivo microenvironment, it is evident that none of these molecules has an exclusive role and that MSC-mediated immunoregulation is mediated by a combination of several molecules, which do not exert their effects in the same direction.

One potential way that MSCs cells could inhibit proliferation of immune cells is their ability to induce Treg cells. Therefore, we next aimed to investigate the effect of MenSCs on induction of Treg lymphocyte population. We found that in the absence of inflammatory cytokines, MenSCs did not induce Tregs, neither did they decrease their frequency. MenSCs can secrete a baseline levels of IL-6 and TGF $\beta$ in proinflammatory environment [65], which could be increased in an allogeneic cell culture system. In a mouse GVHD model, the inhibition of the IL-6 signaling pathway markedly reduced pathologic damage through a significant increase in the absolute number of Tregs [66]. Indeed, IL-6 could induce STAT3-mediated T cell production of IL-10, a cytokine with Treg induction capacity [67]. Similarly, our results showed that higher levels of IL-10 were produced in MenSCs-T cell co-culture supernatant and that inhibition of IL-10 or TGF- $\beta$ significantly inhibited the induction of Tregs. The crucial impact of these cytokines on Treg generation has already been reported. Moreover, induction and propagation of Tregs by MSCs are closely related to IL-10 and TGF- $\beta$ cytokines [68]. We showed that treatment of MenSCs with IFN- $\gamma$ and IL-1 $\beta$ led to increased level of IDO generation, a finding which is in line with our previous findings [46]. IDO dominantly controls the generation and 
functional status of Tregs in response to inflammatory stimuli, which could potentially lead to generation of Tregs.

Finally, we showed that Tregs generated in the presence of MenSCs are functionally active and could prevent proliferation of PBMCs activated with anti-CD3/CD28 antibodies and IL-2. Similar results have also been reported for other sources of MSCs either in mixed lymphocyte reaction [27, 69-71]. It seems that higher immunosuppressive phenotype in Tregs generated in the presence of MSCs is due to the induction of these cells in an inflammatory milieu.

\section{Conclusion}

Collectively, we showed here that, in contrast to other sources of stem cells, MenSCs have a supportive effect on the proliferation of $\mathrm{CD} 4+\mathrm{T}$ lymphocytes and reduced percentage of Tregs unless they were first primed with pro-inflammatory cytokines. Pro-inflammatory cytokines-primed MenSCs could enhance functionally active Tregs and suppress $\mathrm{T}$ cell proliferation, a finding which support their role as the main regulator of the endometrial immune microenvironment during pregnancy.

\begin{abstract}
Abbreviations
1-MT: 1-methyl tryptophan; ASCs: adipose-derived stem cells; AT-MSCs: adipose tissue-derived multipotent stromal cells; BMDC: bone marrowderived DC; BMSCs: bone marrow mesenchymal stem cells; CB-MSCs: cord blood-derived mesenchymal stem cells; CFSE: 5,6-carboxyfluorescein diacetate succinimidyl ester; COX-2: cyclooxygenase-2; DC: dendritic cell; DSCs: decidua-derived stem cells; eMSCs: endometrial stromal/stem cells; GVHD: graft versus host disease; HBV: hepatitis B virus; $\mathrm{HCV}$ : hepatitis C virus: hES-MSCs: human embryonic stem cell-derived mesenchymal stromal cells; HIV: human immunodeficiency virus; ICAM-1: intercellular adhesion molecule 1; IDO: indoleamine-pyrrole 2,3-dioxygenase; IFN- - : interferon gamma; IGFs: insulin-like growth factors; IGFBP: insulin-like growth factor-binding protein; IL$1 \beta$ : interleukin 1 beta; IL-2: interleukin 2; IL-6: interleukin 6; IL-10: interleukin 10; MenSCs: menstrual stromal/stem cells; MLR: mixed lymphocyte reaction; NK: natural killer cell; Oct-4: octamer-binding transcription factor 4; PBMCs: peripheral blood mononuclear cells; PGE2: prostaglandin E2; SSEA-4: stage-specific embryonic antigen 4; STAT3: signal transducer and activator of transcription 3; TGF- $\beta$ : transforming growth factor beta; TH1: type $1 \mathrm{~T}$ helper cells; TH2: type 2T helper cells; TNF-a: tumor necrosis factor alpha; Tregs: regulatory $T$ cells; VCAM-1: vascular cell adhesion protein 1.
\end{abstract}

\section{Supplementary Information}

The online version contains supplementary material available at https://doi. org/10.1186/s13287-021-02603-3.

Additional file 1: Fig. S1. Differentiation of MenSCs into adipocytes, osteoblasts and chondrocytes. MenSCs were differentiated toward adipocytes, osteoblasts and chondrocytes and the extend of differentiation was evaluated using Alizarin red, Alcian blue and Oil Red O staining, respectively. Undifferentiated cells served as controls (A). Immunophenotyping of MenSCs was carried out using a panel of mesenchymal and hematopoietic markers (B).

\section{Acknowledgements}

We would like to express our sincere thanks to department of immunology, Tehran University of Medical Sciences (TUMS) which provided all facilities needed to perform the experiments conducted in this research project.

\section{Authors' contributions}

M.A. did collection and/or assembly of data, data analysis, manuscript writing. M.B. and S.N. performed data analysis and interpretation. A.G., M.R.S., and S.M. done collection and/or assembly of data. F.S. and A.H.Z. were involved in conception and design, data analysis and interpretation, manuscript writing, and final approval of manuscript. All the authors read and approved the final manuscript.

\section{Funding}

This research was supported by grants from Tehran University of Medical Sciences (No: 95-04-27-33245) and Avicenna Research Institute (No: 940402-002).

\section{Availability of data and materials}

All the datasets used or analyzed in this study are available from corresponding author on reasonable request.

\section{Declarations}

\section{Ethics approval and consent to participate}

Ethics Committee for medical research of the Avicenna Research Institute (ARI) approved the study (Ethical Code: 940402-002). All participants gave informed consent before menstrual blood donation.

\section{Consent for publication}

Not applicable.

\section{Competing interests}

The authors declare no competing interests.

\section{Author details}

'Department of Immunology, School of Public Health, Tehran University of Medical Sciences, P.O. Box: 1417613151 , Tehran, Iran. ${ }^{2}$ Reproductive Biotechnology Research Center, Avicenna Research Institute, ACECR, Tehran, Iran. ${ }^{3}$ Immunology Research Center, Institute of Immunology and Infectious Diseases, Iran University of Medical Sciences, Tehran, Iran.

Received: 24 May 2021 Accepted: 23 September 2021

Published online: 09 October 2021

\section{References}

1. Aluvihare VR, Kallikourdis M, Betz AG. Regulatory T cells mediate maternal tolerance to the fetus. Nat Immunol. 2004;5(3):266.

2. Somerset DA, Zheng Y, Kilby MD, Sansom DM, Drayson MT. Normal human pregnancy is associated with an elevation in the immune suppressive CD25+CD4+ regulatory T-cell subset. Immunology. 2004;112(1):38-43.

3. Arruvito L, Sanz M, Banham AH, Fainboim L. Expansion of CD4+ CD25+ and FOXP3 + regulatory T cells during the follicular phase of the menstrual cycle: implications for human reproduction. J Immunol. 2007;178(4):2572-8.

4. Leber A, Teles A, Zenclussen AC. Regulatory T cells and their role in pregnancy. Am J Reprod Immunol. 2010;63(6):445-59.

5. Kallikourdis M, Betz AG. Periodic accumulation of regulatory T cells in the uterus: preparation for the implantation of a semi-allogeneic fetus? PLoS ONE. 2007;2(4):e382.

6. Heikkinen J, Möttönen M, Alanen A, Lassila O. Phenotypic characterization of regulatory $T$ cells in the human decidua. Clin Exp Immunol. 2004;136(2):373-8.

7. Sasaki Y, Sakai M, Miyazaki S, Higuma S, Shiozaki A, Saito S. Decidual and peripheral blood CD4+ CD25+ regulatory T cells in early pregnancy subjects and spontaneous abortion cases. MHR: basic science of reproductive medicine. Mol Hum Reprod. 2004;10(5):347-53. 
8. Zhao J, Zeng Y, Liu Y. Fetal alloantigen is responsible for the expansion of the CD4+ CD25+ regulatory T cell pool during pregnancy. J Reprod Immunol. 2007;75(2):71-81.

9. Teles A, Schumacher A, Kühnle MC, Linzke N, Thuere C, Reichardt P, et al. Control of uterine microenvironment by Foxp $3+$ cells facilitates embryo implantation. Front Immunol. 2013;4:158.

10. Teles A, Thuere C, Wafula PO, El-Mousleh T, Zenclussen ML, Zenclussen AC. Origin of Foxp3+ cells during pregnancy. Am J Clin Exp Immunol. 2013:2(3):222.

11. Polanczyk MJ, Carson BD, Subramanian S, Afentoulis M, Vandenbark AA, Ziegler SF, et al. Cutting edge: estrogen drives expansion of the CD4+ CD25+ regulatory T cell compartment. J Immunol. 2004;173(4):2227-30.

12. Lee JH, Lydon JP, Kim CH. Progesterone suppresses the $m$ TOR pathway and promotes generation of induced regulatory $T$ cells with increased stability. Eur J Immunol. 2012;42(10):2683-96.

13. Baratelli F, Lin Y, Zhu L, Yang S-C, Heuzé-Vourch N, Zeng G, et al. Prostaglandin E2 induces FOXP3 gene expression and T regulatory cell function in human CD4+T cells. J Immunol. 2005;175(3):1483-90.

14. Chen W, Jin W, Hardegen N, Lei K, Li L, Marinos N, et al. Conversion of peripheral $C D 4+C D 25$ - naive $T$ cells to $C D 4+C D 25+$ regulatory T cells by TGF- $\beta$ induction of transcription factor Foxp3. J Exp Med. 2003;198(12):1875-86.

15. Kudo Y, Boyd C, Spyropoulou I, Redman C, Takikawa O, Katsuki T, et al. Indoleamine 2, 3-dioxygenase: distribution and function in the developing human placenta. J Reprod Immunol. 2004;61 (2):87-98.

16. Munn DH, Zhou M, Attwood JT, Bondarev I, Conway SJ, Marshall B, et al. Prevention of allogeneic fetal rejection by tryptophan catabolism. Science. 1998;281(5380):1191-3.

17. Ban Y, Chang Y, Dong B, Kong B, Qu XJ. Indoleamine 2, 3-dioxygenase levels at the normal and recurrent spontaneous abortion fetal-maternal interface. Int J Med Res. 2013:41(4):1135-49.

18. Fallarino F, Grohmann U, You S, McGrath BC, Cavener DR, Vacca C, et al. The combined effects of tryptophan starvation and tryptophan catabolites down-regulate $T$ cell receptor $\zeta$-chain and induce a regulatory phenotype in naive T cells. J Immunol. 2006;176(11):6752-61.

19. Fallarino F, Grohmann U, Vacca C, Bianchi R, Orabona C, Spreca A, et al. T cell apoptosis by tryptophan catabolism. Cell Death Differ. 2002:9(10):1069-77.

20. Lee JH, Ulrich B, Cho J, Park J, Kim CH. Progesterone promotes differentiation of human cord blood fetal T cells into T regulatory cells but suppresses their differentiation into Th17 cells. J Immunol. 2011:187(4):1778-87.

21. Robertson SA, Prins JR, Sharkey DJ, Moldenhauer LM. Seminal fluid and the generation of regulatory $T$ cells for embryo implantation. Am J Reprod Immunol. 2013;69(4):315-30.

22. Pohanka M, Hampl R, Sterzl I, Starka L. Steroid hormones in human semen with particular respect to dehydroepiandrosterone and its immunomodulatory metabolites. Endocr Regul. 2002;36(2):79-86.

23. Robertson SA, Ingman WV, O'Leary S, Sharkey DJ, Tremellen KP. Transforming growth factor $\beta$ - a mediator of immune deviation in seminal plasma. J Reprod Immunol. 2002;57(1-2):109-28.

24. Guerin LR, Moldenhauer LM, Prins JR, Bromfield JJ, Hayball JD, Robertson SA. Seminal fluid regulates accumulation of FOXP3 + regulatory T cells in the preimplantation mouse uterus through expanding the FOXP3+ cell pool and CCL19-mediated recruitment. Biol Reprod. 2011;85(2):397-408.

25. Deshmukh H, Way SS. Immunological basis for recurrent fetal loss and pregnancy complications. Annu Rev Pathol. 2019;14:185-210.

26. Aggarwal S, Pittenger MF. Human mesenchymal stem cells modulate allogeneic immune cell responses. Blood. 2005;105(4):1815-22.

27. Prevosto C, Zancolli M, Canevali P, Zocchi MR, Poggi A. Generation of CD4+ or CD8+ regulatory T cells upon mesenchymal stem cell-lymphocyte interaction. Haematologica. 2007;92(7):881-8.

28. Engela AU, Hoogduijn MJ, Boer K, Litjens NH, Betjes MG, Weimar W, et al. Human adipose-tissue derived mesenchymal stem cells induce functional de-novo regulatory T cells with methylated FOXP3 gene DNA. Clin Exp Immunol. 2013;173(2):343-54

29. Gonzalez-Rey E, Gonzalez MA, Varela N, O'Valle F, Hernandez-Cortes P, Rico $L$, et al. Human adipose-derived mesenchymal stem cells reduce inflammatory and T cell responses and induce regulatory T cells in vitro in rheumatoid arthritis. Ann Rheum Dis. 2010;69(01):241-8.
30. Yang X, Devianti M, Yang YH, Ong YR, Tan KS, Gurung S, Tan J, Zhu D, Lim R, Gargett CE, Deane J. Endometrial mesenchymal stem/stromal cell modulation of T cell proliferation. Reproduction. 2018;1(aop).

31. Caballero-Campo P, Domínguez F, Coloma J, Meseguer M, Remohí J, Pellicer A, et al. Hormonal and embryonic regulation of chemokines IL-8, MCP-1 and RANTES in the human endometrium during the window of implantation. Mol Hum Reprod. 2002;8(4):375-84.

32. Sun B, Nasu K, Fukuda J, Mine S, Nishida M, Miyakawa IJ. Expression of macrophage inflammatory protein-3a in an endometrial epithelial cell line, HHUA, and cultured human endometrial stromal cells. Mol Hum Reprod. 2002;8(10):930-3.

33. Patel AN, Park E, Kuzman M, Benetti F, Silva FJ, Allickson JG. Multipotent menstrual blood stromal stem cells: isolation, characterization, and differentiation. Cell Transplant. 2008;17(3):303-11.

34. Kazemnejad S, Akhondi M-M, Soleimani M, Zarnani AH, Khanmohammadi M, Darzi S, et al. Characterization and chondrogenic differentiation of menstrual blood-derived stem cells on a nanofibrous scaffold. Int J Artif Organs. 2012;35(1):55-66.

35. Khanmohammadi M, Khanjani S, Bakhtyari MS, Zarnani AH, Edalatkhah $\mathrm{H}$, Akhondi MM, et al. Proliferation and chondrogenic differentiation potential of menstrual blood-and bone marrow-derived stem cells in two-dimensional culture. Int J Hematol. 2012;95(5):484-93.

36. Darzi S, Zarnani AH, Jeddi-Tehrani M, Entezami K, Mirzadegan E, Akhondi $\mathrm{MM}$, et al. Osteogenic differentiation of stem cells derived from menstrual blood versus bone marrow in the presence of human platelet releasate. Tissue Eng Part A. 2012;18(15-16):1720-8.

37. Kazemnejad S, Zarnani A-H, Khanmohammadi M, Mobini S. Chondrogenic differentiation of menstrual blood-derived stem cells on nanofibrous scaffolds. Stem cell nanotechnology. Berlin: Springer; 2013. p. $149-69$.

38. Khanmohammadi M, Khanjani S, Edalatkhah H, Zarnani A, Heidari-Vala H, Soleimani $\mathrm{M}$, et al. Modified protocol for improvement of differentiation potential of menstrual blood-derived stem cells into adipogenic lineage. Cell Prolif. 2014;47(6):615-23.

39. Murphy MP, Wang H, Patel AN, Kambhampati S, Angle N, Chan K, et al. Allogeneic endometrial regenerative cells: an" off the shelf solution" for critical limb ischemia? J Transl Med. 2008;6(1):45.

40. Nikoo S, Ebtekar M, Jeddi-Tehrani M, Shervin A, Bozorgmehr M, Kazemnejad S, et al. Effect of menstrual blood-derived stromal stem cells on proliferative capacity of peripheral blood mononuclear cells in allogeneic mixed lymphocyte reaction. J Obstet Gynaecol Res. 2012;38(5):804-9.

41. Meng X, Ichim TE, Zhong J, Rogers A, Yin Z, Jackson J, et al. Endometrial regenerative cells: a novel stem cell population. J Transl Med. 2007:5(1):57.

42. Musina R, Belyavski A, Tarusova O, Solovyova E, Sukhikh G. Endometrial mesenchymal stem cells isolated from the menstrual blood. Bull Exp Biol Med. 2008;145(4):539-43.

43. Bozorgmehr M, Moazzeni SM, Salehnia M, Sheikhian A, Nikoo S, Zarnani A-H. Menstrual blood-derived stromal stem cells inhibit optimal generation and maturation of human monocyte-derived dendritic cells. Immunol Lett. 2014;162(2):239-46.

44. Shokri M-R, Bozorgmehr M, Ghanavatinejad A, Falak R, Aleahmad $M$, Kazemnejad S, et al. Human menstrual blood-derived stromal/ stem cells modulate functional features of natural killer cells. Sci Rep. 2019;9(1):10007.

45. Kazemnejad S, Najafi R, Zarnani AH, Eghtesad S. Comparative effect of human platelet derivatives on proliferation and osteogenic differentiation of menstrual blood-derived stem cells. Mol Biotechnol. 2014;56(3):223-31.

46. Nikoo S, Ebtekar M, Jeddi-Tehrani M, Shervin A, Bozorgmehr M, Vafaei $S$, et al. Menstrual blood-derived stromal stem cells from women with and without endometriosis reveal different phenotypic and functional characteristics. Mol Hum Reprod. 2014;20(9):905-18.

47. Ghanavatinejad A, Bozorgmehr M, Shokri MR, Aleahmad M, Tavakoli M, Shokri F, Zarnani AH. MenSCs exert asupportive role in establishing a pregnancy-friendly microenvironment by inhibiting TH17 polarization. $J$ Reprod Immunol. 2021;144:103252.

48. Aleahmad M, Ghanavatinejad A, Bozorgmehr M, Shokri M-R, Nikoo S, Tavakoli M, et al. Menstrual blood-derived stromal stem cells augment $\mathrm{cd} 4+\mathrm{t}$ cells proliferation. Avicenna J Med Biotechnol. 2018;10(3):183. 
49. Bozorgmehr M, Gurung S, Darzi S, Nikoo S, Kazemnejad S, Zarnani A-H, et al. Endometrial and menstrual blood mesenchymal stem/stromal cells: biological properties and clinical application. Front Cell Dev Biol. 2020;8:497.

50. Teague TK, Marrack P, Kappler JW, Vella AT. IL-6 rescues resting mouse T cells from apoptosis. J Immunol. 1997;158(12):5791-6.

51. Ayroldi E, Zollo O, Cannarile L, D'Adamio F, Grohmann U, Delfino DV, et al. Interleukin-6 (IL-6) prevents activation-induced cell death: IL-2independent inhibition of Fas/fasL expression and cell death. Blood. 1998;92(11):4212-9.

52. Uccelli A, Moretta L, Pistoia V. Mesenchymal stem cells in health and disease. Nat Rev Immunol. 2008;8(9):726-36.

53. Luz-Crawford P, Torres MJ, Noël D, Fernandez A, Toupet K, AlcayagaMiranda $F$, et al. The immunosuppressive signature of menstrual blood mesenchymal stem cells entails opposite effects on experimental arthritis and graft versus host diseases. Stem cells. 2016;34(2):456-69.

54. Li O, Tormin A, Sundberg B, Hyllner J, Le Blanc K, Scheding S. Human embryonic stem cell-derived mesenchymal stroma cells (hES-MSCs) engraft in vivo and support hematopoiesis without suppressing immune function: implications for off-the shelf ES-MSC therapies. PLoS ONE. 2013;8(1):e55319.

55. Deuse T, Stubbendorff M, Tang-Quan K, Phillips N, Kay MA, Eiermann T, et al. Immunogenicity and immunomodulatory properties of umbilical cord lining mesenchymal stem cells. Cell Transplant. 2011;20(5):655-67.

56. Najar M, Raicevic G, Fayyad-Kazan H, De Bruyn C, Bron D, Toungouz $\mathrm{M}$, et al. Impact of different mesenchymal stromal cell types on T-cell activation, proliferation and migration. Int Immunopharmacol. 2013;15(4):693-702

57. Ren G, Zhao X, Zhang L, Zhang J, L'Huillier A, Ling W, et al. Inflammatory cytokine-induced intercellular adhesion molecule-1 and vascular cell adhesion molecule-1 in mesenchymal stem cells are critical for immunosuppression. J Immunol. 2010;184(5):2321-8.

58. Ma S, Xie N, Li W, Yuan B, Shi Y, Wang Y. Immunobiology of mesenchymal stem cells. Cell Death Differ. 2014;21(2):216.

59. Burr SP, Dazzi F, Garden OA. Mesenchymal stromal cells and regulatory T cells: the Yin and Yang of peripheral tolerance? Immunol Cell Biol. 2013;91(1):12-8.

60. Liu C-H, Hwang S-M. Cytokine interactions in mesenchymal stem cells from cord blood. Cytokine. 2005;32(6):270-9.

61. Chen K, Wang D, Du WT, Han Z-B, Ren H, Chi Y, et al. Human umbilical cord mesenchymal stem cells hUC-MSCs exert immunosuppressive activities through a PGE2-dependent mechanism. Clin Immunol. 2010;135(3):448-58.
62. Wang D, Chen K, Du WT, Han Z-B, Ren H, Chi Y, et al. CD14+ monocytes promote the immunosuppressive effect of human umbilical cord matrix stem cells. Exp Cell Res. 2010;316(15):2414-23.

63. Gieseke F, Schütt B, Viebahn S, Koscielniak E, Friedrich W, Handgretinger R, et al. Human multipotent mesenchymal stromal cells inhibit proliferation of PBMCs independently of IFNYR1 signaling and IDO expression. Blood. 2007:110(6):2197-200.

64. Harizi H, Gualde N. Pivotal role of PGE2 and IL-10 in the cross-regulation of dendritic cell-derived inflammatory mediators. Cell Mol Immunol. 2006;3(4):271-7.

65. Gargett CE, Schwab KE, Deane JA. Endometrial stem/progenitor cells: the first 10 years. Hum Reprod Update. 2015;22(2):137-63.

66. Chen X, Das R, Komorowski R, Beres A, Hessner MJ, Mihara M, et al. Blockade of interleukin-6 signaling augments regulatory T-cell reconstitution and attenuates the severity of graft-versus-host disease. Blood. 2009;114(4):891-900.

67. Stumhofer JS, Silver JS, Laurence A, Porrett PM, Harris TH, Turka LA, et al. Interleukins 27 and 6 induce STAT3-mediated T cell production of interleukin 10. Nat Immunol. 2007:8(12):1363.

68. Hong JW, Lim JH, Chung CJ, Kang TJ, Kim TY, Kim YS, et al. Immune tolerance of human dental pulp-derived mesenchymal stem cells mediated by CD4+ CD25+ FoxP3+ regulatory T-cells and induced by TGF- $\beta 1$ and IL-10. Yonsei Med J. 2017;58(5):1031-9.

69. Miyagawa I, Nakayamada S, Nakano K, Yamagata K, Sakata K, Yamaoka $\mathrm{K}$, et al. Induction of regulatory $T$ cells and its regulation with insulin-like growth factor/insulin-like growth factor binding protein-4 by human mesenchymal stem cells. J Immunol. 2017;199(5):1616-25.

70. Lee H-J, Kim S-N, Jeon M-S, Yi T, Song SU. ICOSL expression in human bone marrow-derived mesenchymal stem cells promotes induction of regulatory T cells. Sci Rep. 2017;7:44486.

71. English K, Ryan J, Tobin L, Murphy M, Barry F, Mahon BP. Cell contact, prostaglandin $\mathrm{E} 2$ and transforming growth factor beta 1 play nonredundant roles in human mesenchymal stem cell induction of CD4+ CD25Highforkhead box P3+ regulatory T cells. Clin Exp Immunol. 2009:156(1):149-60.

\section{Publisher's Note}

Springer Nature remains neutral with regard to jurisdictional claims in published maps and institutional affiliations.

Ready to submit your research? Choose BMC and benefit from:

- fast, convenient online submission

- thorough peer review by experienced researchers in your field

- rapid publication on acceptance

- support for research data, including large and complex data types

- gold Open Access which fosters wider collaboration and increased citations

- maximum visibility for your research: over $100 \mathrm{M}$ website views per year

At BMC, research is always in progress.

Learn more biomedcentral.com/submissions 